\title{
Free-Standing Clinic
}

National Cancer Institute

\section{Source}

National Cancer Institute. Free-Standing Clinic. NCI Thesaurus. Code C105743.

A facility that provides medical care that can be safely performed without requiring inpatient hospital care. 